\title{
Saroja Raman, Agricultural Sustainability: Principles, Processes and Prospects
}

\author{
The Haworth Press, Inc. New York 475 pp. \\ ISBN-13:978-1-56022-310-8
}

\author{
Anton J. Haverkort
}

Received: 19 December 2006 / Accepted: 28 December 2006 / Published online: 23 January 2007

(C) Springer Science+Business Media B.V. 2007

Dr. Raman has worked for over thirty-five years at agricultural universities in India where she compiled the information published in the book. A foreword written by Dr. M.S. Swaminathan describes the "green revolution" as the product of an interaction between crop genotypes and agronomic management with particular reference to soil fertility enhancement and irrigation water availability. He expresses the hope that the book will be read and used for launching an Evergreen Revolution in agriculture.

The author defines sustainable agriculture as the maintenance of the long-term productivity of a system in an environmentally conserving and safe manner coupled with economic viability, social justice and equity for the grower. Here we recognize the three P's usually associated with sustainability: the $\mathrm{P}$ for Planet (environment), People (well-being) and profit (for all involved in agricultural supply chains). The book Agricultural Sustainability however associates sustainability with three other less descriptive but more activating P's of Principles, Processes and Prospects. This is also how the book is organized in three parts.

\footnotetext{
A. J. Haverkort $(\square)$

Plant Research International,

Wageningen University and Research Centre,

P. O. Box 16, Wageningen, 6700 AA, The Netherlands

e-mail: anton.haverkort@wur.nl
}

The first part deals with the historic evolution of the concept of sustainability that really became an issue because of uncontrolled population growth required increasing demand for food. Different agricultural systems in the developed, fairly developed (e.g., India) and least developed countries are compared to illustrate that sustainability is a context-based issue and that not a generic globally applicable sustainable production system can be generated. The second part explains that the availability of resources-soil, water, minerals, energy, biodiversity, chemicalsand their proper management are key to promote agricultural sustainability. The role of science and technology as a facilitator for sustainable use of resources is treated. Here attention is given to the need to measure agricultural sustainability in a quantitative way although the author finds it "a complex and nebulous task". The third P of Prospects is dealt with in the last section where vision documents of international agencies (FAO, IFPRI, World Bank) are portrayed with emphasis on poverty reduction and the importance of preventing soil degradation and enhancing income generation to assure livelihood for the farming community to ensure sustainable food security and minimum human development standards. This is illustrated with case studies from India and China.

The book is very readable and treats the subject with great accessibility. The subjects is 
dealing with sustainability at the global level in a holistic way and shows the need to drastically alter agricultural production systems at the local level to assure an optimal use of resources. As such the book will assist policymakers in directing future actions regarding the deployment of human and financial resources-especially regarding research and development and stimulation of sustainable practices.

"Agricultural Sustainability" is descriptive of the present situation and the global trends such as changing diets with people eating more animal products requiring increased supply of animal feed, global climatic change and the rapid increase of biofuels are mentioned only marginally. It is not a handbook for scientists and exten- sionists to try and implement improved practices. Optimal use of resources involves the complex management of the $\mathrm{G} \times \mathrm{E} \times \mathrm{M}$ interaction: genetic, environmental and managerial resources. "Agricultural Sustainability" having convinced the reader of the urge to improve agricultural production and hinting ways forward in a generic way, subsequently would require more in depth information on required science and technology to achieve these aims. There are of modern breeding methods that yield improved varieties regarding resource use, communication technologies allowing intelligent decision support and precision farming techniques. They are treated as requirements for sustainable agricultural production at the global level. 